\title{
AMENDMENTS
}

\section{Publisher Correction: Send in the senolytics}

Elie Dolgin

Correction to: Nature Biotechnology https://doi.org/10.1038/s41587-020-00750-1, published online 12 November 2020.

In this News Feature, a parenthetical sentence reading "(Although van Deursen left the Minnesota research hospital earlier this year after allegations of bullying, a Mayo Clinic spokesperson states that the integrity of the lab's results has not been called into question and that no published papers are being retracted)," located at the end of the first paragraph of section "Zombie cells," has been removed.

The original News Feature has been corrected online.

Published online: 6 September 2021

https://doi.org/10.1038/s41587-021-01073-5

() The Author(s), under exclusive licence to Springer Nature America, Inc. 2021 